\title{
Changing the design of a synchronous motor after testing
}

\author{
Timur Petrov ${ }^{1,}$, Vladimir Kornilov ${ }^{1}$, Alfred Safin ${ }^{1}$, Nikita Kuvshinov ${ }^{1}$, Alexey Tsvetkov ${ }^{1}$, and Ramil Gibadullin ${ }^{1}$ \\ ${ }^{1}$ Kazan State Power Engineering University, Kazan, Russia
}

\begin{abstract}
In the course of work on the project, we have created a permanent magnet synchronous motor, which will be effectively used in the oil industry, or rather 2 models: 15- and 55-kW motors. After the tests carried out, the problem with the achievement of the specified value of the efficiency of the engines was clarified, and it was necessary to solve this problem without significantly changing the design. One of the solutions is presented in the article.
\end{abstract}

\section{Introduction}

The goal of the project is to create intelligent control stations and a new series of Russian highly efficient valve motors for sucker rod pumping units designed to increase oil production, optimize the technological process, significantly reduce the impact of the "human" factor and improve industrial safety.

The modern approach to the automation of oil production processes dictates stringent requirements for software and hardware complexes for monitoring and control of sucker rod pumps. This is due to the depletion of resources in oil reservoirs, the increase in the cost of electricity, the desire of oil companies to reduce the cost of well workover and more efficiently use their personnel. In order to save it, a frequency-controlled drive of the pumping machine is used.

Existing well control systems for monitoring are easy to use. However, there are some disadvantages: individual measurements and tests have to be carried out, there are no automated tools and the complexity of commissioning. It is worth noting that specialists are required to attend and supervise the work on the construction site. Depending on the actual situation in oil fields, wells are most often grouped.

By using centralized management, intelligent control, and split management, configuration can be greatly simplified and maintenance is reduced. The main development trend in solving this problem is the creation of digital intelligent field management systems. Much attention is now paid to the transition to fully automatic control of electric drives and remote control of parameters at the control room. The use of intelligent energy-saving control stations for the oil pumping unit based on synchronous motors allows to optimize oil production by increasing the volume of production and saving energy resources. The main disadvantage of such control stations is their high cost, which is a limiting factor for widespread use.

The carried out literary review showed that the issues of control stations for sucker rod pumps, dynamometry, wattmetering, and the development of synchronous electric motors are well covered $[1,2]$.

On the other hand, the literature insufficiently reflects the problems of frequency regulation of synchronous motors, as well as the capabilities of intelligent control stations that would increase the level of oil production, optimize the technological process, significantly reduce the influence of the "human" factor and improve industrial safety [3,4].

During the work, an electric drive was created based on a synchronous electric motor with permanent magnets. A stand was also developed for testing engines, since it is quite expensive to carry out real field tests.

And after various tests, it became clear that the engine (both options) did not have the required characteristics. Basically, tests that measured electromechanical performance.

Justification of the need for change. In the course of experimental studies, a prototype sample of a synchronous electric motor, on the stand at a rated speed of 1000 (750) rpm, did not confirm the declared efficiency $(<0.96)$.

It is not possible to change the frequency Converter, so it is necessary to change the design of the motor to obtain the required characteristics. This paper will present one of the solutions to this problem.

\section{Theoretical aspects}

The established fact unambiguously corresponds to the theory of electromagnetic energy conversion in a synchronous machine with permanent magnets [5], from which it is known that the electromagnetic moment of the motor $M_{d}$ is determined by an expression of the form:

$$
M_{d}=3 / 2 S_{d} \times i_{1 q}
$$

Where :

\footnotetext{
* Corresponding author: tobac15@mail.ru
} 


$$
\begin{aligned}
& S_{d}=p_{n} \times \Psi_{f} \\
& \Psi_{f}=\Phi \times w
\end{aligned}
$$

Accepted designations:

$\mathrm{S}_{\mathrm{d}}$-coefficient of proportionality between the electromagnetic moment $M_{d}$ and the projection ilq, the generalized stator current vector on the orthogonal axis of the rectangular coordinate system $\mathrm{d}-\mathrm{q}$;

$\mathrm{p}_{\mathrm{n}}$ - is the number of pole pairs;

$\Psi_{f}$ - is the vector of the stator flux linkage component from the flux Фof permanent magnets;

$\mathrm{W}$ - is the number of turns of the stator winding.

To increase the efficiency, you can increase the rated current, but the negative effect of increasing the rated current for the prototype motor, first of all, is that it is necessary to make significant adjustments to the design of the frequency converter, which cannot provide the formation of such currents. Secondly, it will be necessary to change the winding data in the direction of increasing the cross-section of the phase conductors based on an updated thermal calculation [6,7].

In order not to change the design of the frequency converter, it is necessary to lower the current value to the level admissible for the converter of $45 \mathrm{~A}$, that is, for a prototype motor, this decrease should be

$$
57-45=12 \text { A or } 12 / 57 \times 100 \%=21 \% .
$$

On the other hand, maintaining the declared power of $15 \mathrm{~kW}$ means maintaining a constant torque of $192 \mathrm{Nm}$ on the shaft. Therefore, at the required current value of $45 \mathrm{~A}$, it is necessary to increase the value of the $\mathrm{S}_{\mathrm{d}}$ coefficient by $21 \%$. But this can be done without changing the main flow of the permanent magnets of the rotor only by increasing the number of winding turns by $21 \%$, which, in terms of the slot filling factor, will not exceed the permissible value of $0.72-0.74$. This is confirmed by a simplified calculation for the $155-1.18$ wire used in the prototype and for the geometric dimensions of the groove.

The geometry of the groove can be approximated in excess by an equilateral trapezoid with a lower base of $6.6 \mathrm{~mm}$ and an upper base of $3 \mathrm{~mm}$ and a height of 25.3 $\mathrm{mm}$, thus the "clear" area will be $(6.6+3) / 2 * 25.3=$ $121.44 \mathrm{~mm}^{2}$. The copper conductor has a diameter of $1.18+/-0.012 \mathrm{~mm}$ and a thickness of varnish insulation of $0.05 \mathrm{~mm}$, which adds another $1 \mathrm{~mm}$ to the wire diameter, then the cross-sectional area of the wire can be determined with a margin as the area of the described square with a side of $1.28 \mathrm{~mm}$, which is $1,64 \mathrm{~mm}^{2}$. Thus, $121.44 / 1.64=74$ conductors are needed to completely fill the slot. According to the design documentation, one coil of the winding contains 18 turns, therefore, with a double-layer winding, 36 conductors are laid in the groove. If the number of turns in the coil is increased by $21 \%$, that is, by 4 turns, then 44 conductors will be laid in the groove, which will be $44 / 74=0.59$ of the theoretically possible. There remains a margin for phaseto-phase insulation and wedges for fixing the windings in the groove.
Similar reasoning is applicable for a prototype motor $-15 \mathrm{~kW} 1000 \mathrm{rpm}$, supply voltage frequency $50 \mathrm{~Hz}$ (nominal current value is not specified).

To verify the corrective calculations using certified software, these calculations should be compared with the results of experimental studies of prototypes at the stand.

Estimation of the value of the coefficient of a synchronous motor in order to check the achievement of a given value of flux linkage $\Psi f$ after correcting the number of turns of the stator winding of the motor [8$13]$.

It is proposed to check the results of two experiments:

a) An experiment to determine the electromotive force(EMF) when the rotor rotates from the loading motor at the rated speed [14];

b) An experiment to determine the rated current consumed by the motor at the rated load torque, rated frequency of the supply voltage and rated speed [15].

\section{Checking changes based simulation}

To verify the corrective calculations using certified software, these calculations should be compared with the results of experimental studies of prototypes at the stand.

Table 1.Tests of a prototype engine $-15 \mathrm{~kW}$ under load when powered by a frequency converter $-15 \mathrm{~kW}$, frequency $50 \mathrm{~Hz}$, $750 \mathrm{rpm}$ (from 27.02.2020)

\begin{tabular}{|l|l|l|l|l|l|l|l|}
\hline № & $\begin{array}{l}f, \\
\mathrm{~Hz}\end{array}$ & $\begin{array}{l}\text { Mload } \\
\%\end{array}$ & $\begin{array}{l}\text { Mtorque } \\
\mathrm{Nm}\end{array}$ & $\begin{array}{l}\mathrm{P}_{2}, \\
\mathrm{~kW}\end{array}$ & $\mathrm{I}, \mathrm{A}$ & $\operatorname{Cos} \varphi$ & Notes \\
\hline 1 & 50 & 15 & 81 & 6.3 & 24 & - & \\
\hline 2 & 50 & 20 & 106 & 8.3 & 31 & - & \\
\hline 3 & 50 & 22.8 & 121 & 9.5 & 36 & - & \\
\hline 4 & 50 & 24.8 & 130.7 & 10.3 & 39 & - & \\
\hline 5 & 50 & 26.5 & 139.4 & 10.9 & 42 & - & \\
\hline 6 & 50 & 28.2 & 147.7 & 11.6 & 45 & $0.99 /-$ & $\begin{array}{l}\mathrm{P}_{1}=12.2 ; \\
\text { Efficiency } \\
=0.95\end{array}$ \\
\hline 7 & 50 & 30.2 & 157.4 & 12.36 & 48 & $0.99 /-$ & $\begin{array}{l}\mathrm{P}_{1}=13.02 ; \\
\text { Efficiency } \\
=0.95\end{array}$ \\
\hline
\end{tabular}

Efficiency in items 6 and 7 of Table 1.was 0.95, which does not meet the declared requirements and the power comes out less than the nominal value of $15 \mathrm{~kW}$ (45 $\mathrm{A}$ is the maximum current value for the used converter).

Let's simulate an increase in the number of winding turns by $21 \%$ in the Elcut program to check the change in the efficiency value.

This simulation will be performed by changing the number of Ampere-turns in the slots, followed by the calculation of the torque [16].

First, we will check the model for item 7 , the following results were obtained (table 2). 
Table 2.

\begin{tabular}{|c|c|}
\hline Step & Moment. Nm \\
\hline 0 & 19.89 \\
\hline 1 & 118.58 \\
\hline $1 \_2$ & -132.81 \\
\hline $1 \_3$ & -7.93 \\
\hline $1 \_4$ & 156.67 \\
\hline $1 \_5$ & -221.46 \\
\hline $1 \_6$ & -13.14 \\
\hline $1 \_7$ & 230.96 \\
\hline $1 \_8$ & -256.71 \\
\hline $1 \_9$ & 4.39 \\
\hline $1 \_10$ & 253.78 \\
\hline $1 \_11$ & -221.61 \\
\hline $1 \_12$ & -17.15 \\
\hline $1 \_13$ & 240.34 \\
\hline $1 \_14$ & -125.39 \\
\hline $1 \_15$ & -3.89 \\
\hline $1 \_16$ & 175.93 \\
\hline $1 \_17$ & -71.57 \\
\hline
\end{tabular}

For these results, the rms torque is $157.862 \mathrm{Nm}$, the deviation from the test $(165 \mathrm{Nm})$ is $4.3 \%$, which is an acceptable result. The change schedule is shown in Figure 1.

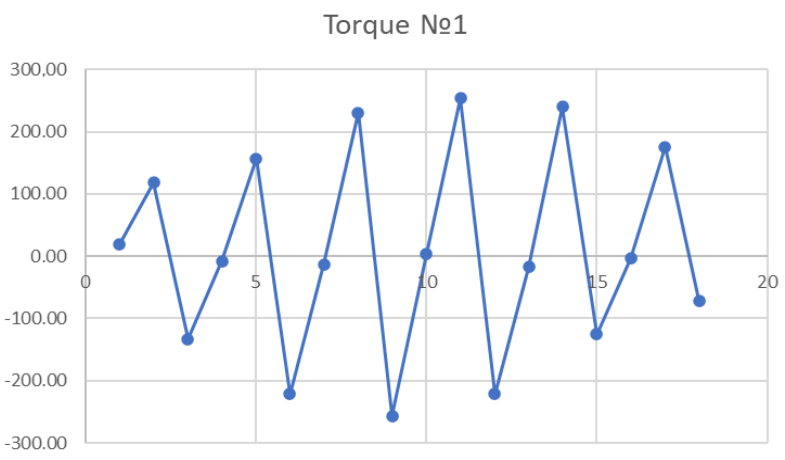

Fig. 1.Torque change at 18 steps (experiment No. 7 of Table 1).

Next, we will check the model for item 6., the following results were obtained (table 3 ).
Table 3.

\begin{tabular}{|c|c|}
\hline Step & Moment, Nm \\
\hline 0 & 30.01 \\
\hline 1 & 142.54 \\
\hline $1 \_2$ & -133.22 \\
\hline 1_3 & -8.08 \\
\hline 1_4 & 155.79 \\
\hline 1_5 & -207.61 \\
\hline 1_6 & -12.21 \\
\hline 1_7 & 218.94 \\
\hline 1_8 & -235.99 \\
\hline 1_9 & 5.89 \\
\hline 1_10 & 236.49 \\
\hline 1_11 & -208.52 \\
\hline 1_12 & -16.03 \\
\hline 1_13 & 226.45 \\
\hline 1_14 & -126.51 \\
\hline 1_15 & -4.23 \\
\hline 1_16 & 172.06 \\
\hline 1_17 & -79.37 \\
\hline & \\
\hline
\end{tabular}

For these results, the rms torque value we get is $147.5 \mathrm{Nm}$, the deviation from the test (155 Nm) is $4.8 \%$, which is an acceptable result. The change graph is shown in Figure 2.

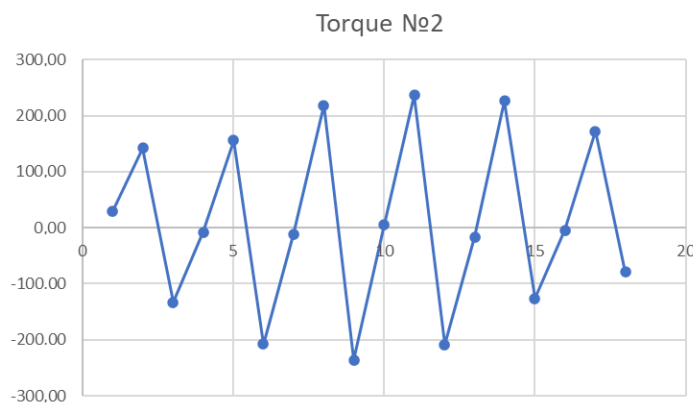

Fig. 2.Torque change at 18 steps (experiment No. 6 of Table 1).

The deviation from the values obtained during the tests is less than $5 \%$, which indicates the adequacy of the model.

For the limit values of the load current (experiments according to clause 6 of Table 1), the values of SD are as follows:

item 6:

$$
\begin{aligned}
& S_{d}=2 M_{d m} / 3 \eta \sqrt{2} * I=0,498 * M_{d m} / I= \\
& =0,498 * 147.7 / 45=1.635
\end{aligned}
$$

With an increase of $21 \%, \mathrm{~S}_{\mathrm{D}}=1.97835$.

For item 6 , when the number of winding turns was changed by $21 \%$, the following results were obtained (table 4). 
Table 4.

\begin{tabular}{|c|c|}
\hline Step & Moment, Nm \\
\hline 0 & 4.70 \\
\hline 1 & 157.25 \\
\hline $1 \_2$ & -176.17 \\
\hline $1 \_3$ & -23.08 \\
\hline $1 \_4$ & 208.95 \\
\hline $1 \_5$ & -288.03 \\
\hline $1 \_6$ & -21.12 \\
\hline $1 \_7$ & 302.23 \\
\hline $1 \_8$ & -334.31 \\
\hline 1_9 & 1.28 \\
\hline 1_10 & 325.66 \\
\hline 1_11 & -285.90 \\
\hline 1_12 & -24.58 \\
\hline 1_13 & 313.50 \\
\hline 1_14 & -168.61 \\
\hline 1_15 & -15.69 \\
\hline 1_16 & 232.19 \\
\hline 1_17 & -104.32 \\
\hline
\end{tabular}

For these results we get the rms torque value of $200.87 \mathrm{Nm}$. $\mathrm{M}_{\mathrm{dm}}$ will be $192 \mathrm{Nm}$. The change graph is shown in Figure 3.

Torque №3

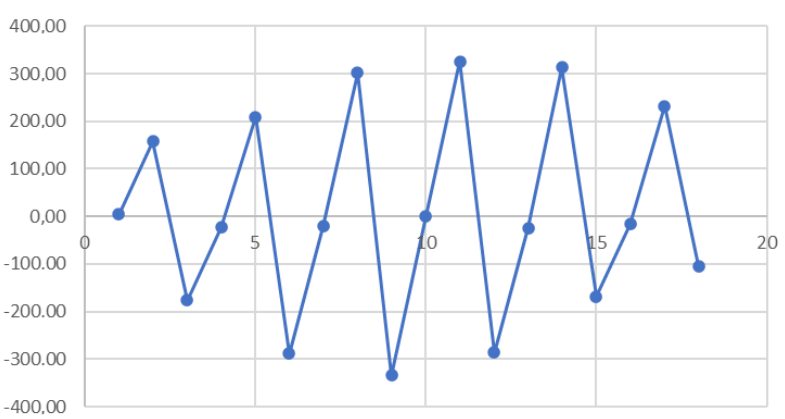

Fig. 3. Change in the moment of change in the number of winding turns by $21 \%$.

When simulating, the $\mathrm{S}_{\mathrm{d}}$ value is as follows:

$$
\begin{aligned}
& S_{d}=2 M_{d m} / 3 \eta \sqrt{2} * I=0,498 * M_{d m} / I= \\
& =0,498 * 192 / 44=2.12
\end{aligned}
$$

The deviation from the calculated value is $7.16 \%$, which is acceptable.

Let us present the results obtained in the form of tables comparing the change in efficiency when the number of winding turns changes by $21 \%$.
Table 5.

\begin{tabular}{|c|c|c|c|}
\hline & $\begin{array}{c}\text { Tests } \\
\text { (table 1) }\end{array}$ & $\begin{array}{c}\text { Model of the } \\
\text { tested engine }\end{array}$ & $\begin{array}{c}\text { Modified } \\
\text { engine model }\end{array}$ \\
\hline $\mathrm{M}, \mathrm{Nm}$ & 147.7 & 147.5 & 192 \\
\hline $\mathrm{P} 2, \mathrm{~kW}$ & 11.598 & 11.583 & 15.077 \\
\hline $\mathrm{P} 1, \mathrm{~kW}$ & 12.2 & 12.2 & 15.647 \\
\hline Efficiency & 0.95 & 0.95 & 0.96 \\
\hline
\end{tabular}

The obtained predicted current values for providing Mnom $=525.31 \mathrm{~N}^{*} \mathrm{~m}$ rated for a frequency of $50 \mathrm{~Hz}$ on the motor shaft - $55 \mathrm{~kW}$ are not acceptable. Therefore, it follows that it is necessary to increase the value of Sd. As in the case with the $15 \mathrm{~kW}$ prototype, you can try to raise the $\mathrm{Sd}$ value by changing the winding design [1720].

Assuming, as in the case of the $15 \mathrm{~kW}$ prototype winding, that it is possible to increase the number of turns by $20 \%$, the motor current value decreases from $173.83 \mathrm{~A}$ to $139 \mathrm{~A}$, and as the experiment showed (see Table 5), this current already corresponds to the operability range synchronous motor.

\section{Conclusion}

After testing, a problem was found with a lower engine efficiency than planned. Changing the design of the frequency converter was not possible, so a solution was chosen with a change in the number of winding turns in the stator slots (by 21\%).

A theoretical justification of this decision was carried out, and then modeling was carried out. The simulation was carried out in Elcut, by changing the number of ampere-turns in the stator slots, the torque was calculated, and then the engine efficiency, which confirmed the reliability of the chosen solution (the engine efficiency reached the planned 96\%).

The analysis of the energy characteristics of the prototype engine showed that the specified nominal power was not achieved at the declared parameters of the nominal modes. To increase the output power without changing the design of the motor rotors and without changing the design of frequency converters (and, consequently, control stations), changes should be made in the design of the stator windings of the motors by increasing the number of winding turns (according to estimated calculations by $20 \%$ ).

To experimentally check the energy characteristics, add additional provisions to the method for testing the engine and the method for testing electric drives to determine the proportionality coefficient based on the results of measuring the EMF of rotation using the FLUKE equipment and the output power P2 and the torque $\mathrm{M}_{\text {load }}$ using the torque sensor M40.

\section{Acknowledgements}

The article was published as part of the project "Creating a Series of Electric Drives Based on Russian HighPerformance Synchronous Motors for Oil Pumping Units Using Wireless Data Communication Systems and an Adaptive Control System for Smart Fields", Agreement 
No. 074-11-2018-020 with the Ministry of Education and Science of the Russian Federation May 30, 2018

\section{References}

[1] I.I. Mazein, A.N. Ustinov, M.V. Tyaktev, A.A. Rybin, D.I. Shishlyannikov, M.M. Tyaktev, The results of pilot tests of promising drives for sucker-rod pumping units Mining equipment and electromechanics 9, 8-14 (2016)

[2] K.F. Fozao, M. Lissouck, F. Lontsi, A. Ngasa, N. Mbanda, Hands-on model of sucker rod pumping facility for oil well production, Journal of Petroleum and Gas Engineering 6, 45-53 (2015)

[3] A.N. Tsvetkov, V.Y. Kornilov, A.R. Safin, N.E. Kuvshinov, T.I. Petrov, A.G. Logacheva, An Experimental Bench for the Study of Electric Drives of a Horsehead Pump, Journal of Advanced Research in Dynamical and Control Systems (JARDCS) 12, 05-SPECIAL ISSUE, 12941298ISSN: 1943-023X. DOI: 10.5373/JARDCS/V12SP5/20201888

[4] S. Miric, A. Tuysuz, J.W. Kolar, Comparative evaluation of linear-rotary actuator topologies for highly dynamic applications, 2017 IEEE International Electric Machines and Drives Conference, IEMDC 2017 (2017)

[5] V.Yu. Kornilov, A.I. Mukhametshin, A.N. Tsvetkov, The system of automated control of the energy characteristics of the asynchronous electric drive of sucker rod pumping units, Nonlinear World 6, 33-39 (2017)

[6] A.N. Tsvetkov, A.R. Safin, I.V. Ivshin, T.I. Petrov, R.Sh. Misbakhov, V.Yu. Kornilov, Adaptive Control System of the Pumping Unit, International Journal of Engineering and Advanced Technology (IJEAT) 8, 5S3 (July 2019). ISSN: 2249-8958

[7] F. Sarapulov, V. Frizen, I. Smolyanov, E. Shmakov, Dynamic study of thermal characteristics of linear induction motors, 2017 15th International Conference on Electrical Machines, Drives and Power Systems, ELMA 2017 - Proceedings, 414418 (2017)

[8] L. Dong, X. Han, L. Hua, J. Lan, W. Zhuang, Effects of the rotation speed ratio of double eccentricity bushings on rocking tool path in a cold rotary forging press, Journal of Mechanical Science and Technology 29, 4, 1619-1628 (2015)

[9] L.L. Myagkov, S.M. Sivachev, E.E. Strizhov, S.P. Chirsky, Topological optimization of a highperformance diesel piston, Dvigatelestroyeniye 2, 310 (2018)

[10]L. Saihi, A. Boutera, Robust Sensorless Sliding Mode Control of PMSM with MRAS and Luenberger Extended Observer 2016 8th International Conference on Modelling, Identification and Control (ICMIC 2016), 48-57 (2016)
[11] T. Lindh, J.-H. Montonen, M. Grachev, M. Niemela, Generating surface dynamometer cards for a suckerrod pump by using frequency converter estimates and a process identification run, International Conference on Power Engineering, Energy and Electrical Drives, 7266353, 416-420 (September 2015)

[12]E.I. Gracheva, O.V. Naumov, A.N. Gorlov, Modelling Characteristics of Reliability LowVoltage Switching Devices on the Basis of Random Checks on the Example of Contactors, Proceedings - 2019 1st International Conference on Control Systems, Mathematical Modelling, Automation and Energy Efficiency, SUMMA 2019, 8947595, 641643 (2019)

[13]C. Li, I.Y. Kim, Multi-material topology optimization for automotive design problems, Proceedings of the Institution of Mechanical Engineers, Part D: Journal of Automobile Engineering 232, 14, 1950-1969 (2018)

[14]D. Wang, D. Zhang, X. Du, X. Wang, Thermal Identification, Model, and Experimental Validation of a Toroidally Wound Mover Linear-Switched Reluctance Machine, IEEE Transactions on Magnetics 54, 3 (2018)

[15] M. Cossale, G. Bramerdorfer, G. Goldbeck, M. Kitzberger, D. Andessner, W. Amrhein, Modeling the Degradation of Relative Permeability in Soft Magnetic Materials, 2018 IEEE Transportation and Electrification Conference and Expo, ITEC 2018, 744-748 (2018)

[16]H. Li, Y. Qian, S. Asgarpoor, J. Bradley, PMSM current management with overcurrent regulation (2019) Conference Proceedings - IEEE Applied Power Electronics Conference and Exposition APEC, 1848-1852 (March 2019)

[17] X. Bei, X. Zhu, D.W. Coit, A risk-averse stochastic program for integrated system design and preventive maintenance planning, European Journal of Operational Research 276, 2, 536-548 (2019)

[18] S. Morimoto, K. Kawamoto, M. Sanada, et. al., Sensorless control strategy for salient-pole PMSM based on extended EMF in rotating reference frame, Proc. 2001 IEEE IAS Annual Meeting 4, 2637-2644 (2011)

[19] V.D. Kovshov, M.E. Sidorov, S.V. Svetlakova, Simulation of the dynamogram of the rocking machine. Leaks in valves, Oil and gas business 3, 47-54 (2005)

[20]P.V. Burkov, S.P. Burkova, V.Y. Timofeev, Justifying a method of balancing crank-and-rod mechanism of mining roadheader, Applied Mechanics and Materials 682, 270-275 (2014) 